\title{
Dynamics of the Market for Corporate Tax-Avoidance Advice
}

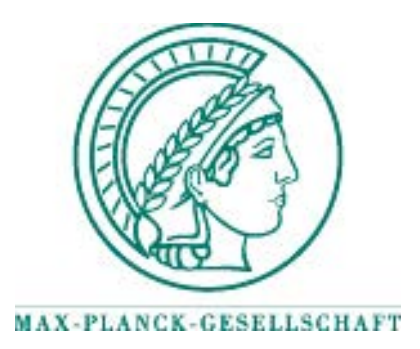

Max Planck Institute for

Tax Law and Public Finance

Department of Business and Tax Law

Department of Public Economics

http:/ / www.tax.mpg.de 
Working papers of the Max Planck Institute for Tax Law and Public Finance Research Paper Series serve to disseminate the research results of work in progress prior to publication to encourage the exchange of ideas and academic debate. Inclusion of a paper in the Research Paper Series does not constitute publication and should not limit publication in any other venue. The preprints published by the Max Planck Institute for Tax Law and Public Finance represent the views of the respective author(s) and not of the Institute as a whole. Copyright remains with the author(s).

Max Planck Institute for Tax Law and Public Finance

Marstallplatz 1

D-80539 Munich

Tel: $\quad+498924246-0$

Fax: $\quad+498924246-501$

E-mail: ssrn@tax.mpg.de

http://www.tax.mpg.de 


\title{
Dynamics of the market for corporate tax-avoidance advice
}

\author{
Kai A. Konrad*
}

April 19, 2018

\begin{abstract}
This paper addresses the current debate about mandatory disclosure rules for aggressive tax-planning models as a means to shorten regulatory delay. It focuses on the dynamic interaction of innovation and imitation of aggressive tax-planning products and governmental tax regulation and highlights the importance of the length of regulatory lag in comparison to the time it takes the tax-consulting industry to imitate newly innovated tax-avoidance products. It reveals synergies between highly innovative tax-consulting firms and the governmental tax legislator/regulator. It suggests that innovative taxconsulting firms may benefit from governmental regulation and may actively try to inform and influence the regulator to shorten but not eliminate the regulatory delay.

Keywords: corporate taxation, tax planning, mandatory disclosure rules, tax consultants, innovation, imitation, tax avoidance, anti-taxavoidance regulation.

JEL classification codes: H26, M48

*Max Planck Institute for Tax Law and Public Finance, Marstallplatz 1, D-80539 Munich, Germany. Email: kai.konrad@tax.mpg.de. I thank Michael P. Devereux and James R. Hines Jr. for helpful discussions at an early stage of this research project, Vidar Christiansen, Tom Gresik, Armin Schmutzler, Wolfgang Schön, Ulrich Schreiber, Tim Stolper and participants in seminars/workshops at Tsinghua University, NHH, CSSSC, Cologne, and CORE for helpful comments. The usual caveat applies.
\end{abstract}




\section{Introduction}

This paper considers the market-nexus between the tax consulting industry, tax regulation, and corporate firms. It studies the dynamics of a market for tax-avoidance products with innovating and imitating tax-consulting firms, and with anti-avoidance tax legislation/regulation. Expert tax consulting firms offer tax optimization advice to corporate firms. Some tax consulting firms may search for and innovate new tax optimization products, other firms may imitate such products, with some time delay. The tax legislator may react and choose whether to implement anti-tax-avoidance regulation. Such regulation may need time before it can be implemented, particularly if an aggressive tax-planning tool has never been used before, and mandatory disclosure rules of aggressive tax-planning models may shorten such a time lag.

We study the role of the time lag by which the government would be able to react and implement anti-tax-avoidance regulation in relation to the time lag needed to imitate newly innovated tax-avoidance products. We find that possible anti-avoidance regulation may, but need not, provide incentives for innovative activities of the consulting industry. If immediate regulation is possible, anti-avoidance regulation can eliminate the scope for aggressive tax-planning tools. A moderate regulatory time lag leads to a stationary equilibrium with innovation and regulation in each period. Anti-avoidance regulation may still be chosen and may successfully increase the tax revenues that emerge in such a framework. An even larger regulatory time lag may lead to an equilibrium with an infinitely repeated cycle. The equilibrium then alternates between periods with innovation and regulation, and periods without such actions. Little tax avoidance is observed in the periods with innovation and regulation. In the other periods the price for tax avoidance products is very low and tax avoidance products are widely used. The equilibrium analysis also finds that synergies exist between highly innovative tax-consulting firms and the governmental regulator. The innovative firms may benefit from governmental regulation, may potentially inform the gov-

ernment and, thereby, influence the size of the regulatory lag towards some prefered size. 
The analysis in the paper is formulated for the case of one country with one tax administration which regulates corporate tax law and the results apply also in a closed economy with a sufficiently complex corporate tax system. However, a broader interpretation of the analysis is the larger, global context. In this, the sector of corporations that look for tax optimization opportunities is not constrained to one country. One might think of the corporate sector inside the OECD or inside the EU. The 'regulator' would then also not be a single nation's government, but a supranational entity such as the OECD or the EU. In fact, this broader interpretation can be particularly relevant as anti-avoidance regulation may require the intervention by an entity such as the OECD or the EU. ${ }^{1}$

From an empirical point of view, the study is partially motivated by the widespread discussion about mandatory disclosure rules for aggressive tax planning strategies. A recent policy initiative in Germany about whether to introduce mandatory disclosure rules for tax-optimizing models at a very early stage might be interpreted as an attempt by which the regulator tries to drastically shorten the regulatory delay. For a legal analysis and assessment of the benefit and cost of this initiative in Germany, see Osterloh-Konrad, Heber and Beuchert (2017).

Such measures are also discussed on the European level. ${ }^{2}$ Whether such measures enable the government(s) to react instantaneously, or whether the regulatory lag is just shortened somewhat, depends on several institutional aspects, given that the lack of information about an aggressive tax-planning opportunity need not be the only reason for delay. But mandatory disclosure rules can potentially speed up regulation and shorten the regulatory lag. The issue of reaction speed is prominently mentioned in the first sentence of the Executive Summary of the OECD's final report on Action 12. of the

\footnotetext{
${ }^{1}$ This also adds possible externalities between the onshore governments affected, and possible conflicts of interest between them. These are potentially relevant issues, but they are not in the focus of the analysis here.

${ }^{2}$ The position of consulting companies on mandatory disclosure rules is also of interest. A position paper by KPMG on the European Commission's public consultation on disincentives for advisors and intermediaries for potentially aggressive tax planning schemes (KPMG 2016) emphasizes the role of the subsidiarity principle and the role of the national tax authorities in this process.
} 
OECD/G20 Base Erosion and Profit Shifting Project (OECD 2015, p.9):

The lack of timely, comprehensive and relevant information on aggressive tax planning strategies is one of the main challenges faced by tax authorities worldwide. Early access to such information provides the opportunity to quickly respond to tax risks through informed risk assessment, audits, or changes to legislation or regulations.

The analysis relies on five main assumptions about the tax-consulting market:

- Demand: To describe the demand for tax planning models, Slemrod (2004) coined the term "The economics of corporate tax selfishness" as a logical implication of shareholder value maximization: the desire and the obligation of company management to reduce the tax burden of the corporation and its shareholders. The various empirical observations suggest firm heterogeneity as regards their ability or willingness to, and their cost of using a tax sheltering/avoidance tool. ${ }^{3}$

- Supply: Professional tax consultants constitute the supply side for such optimization products. ${ }^{4}$ Bankman (1999, p. 1790) highlights the importance of economies of scale which consulting firms may have: "Tax

\footnotetext{
${ }^{3}$ For factors and firm characteristics that make it more or less likely for firms to use a tax shelter see Lisowsky (2010). Dharmapala (2014) surveys the empirical evidence on tax-optimizing behavior.

${ }^{4}$ One of the first writers highlighting the role of tax professionals for tax avoidance is Bankman (1999). Slemrod and Venkatesh (2002) describe the type and size of firms' expenditure for the use of tax professionals. They also report that a majority of the respondent firms were either approached by tax professionals that advertised tax shelters or approached tax professionals on this matter. Slemrod (2004) concludes that "undoubtedly, nearly all large corporations have been solicited by tax shelter promoters, and nearly all have considered pursuing them." Graham et al. (2014) can be interpreted along similar lines. In their paper they report survey-based evidence: "5.2 percent of our respondents answered that tax planning strategies are 'always' pitched as a way to increase earnings, 26.8 percent said it was 'often' the case, 50.7 percent responded that this was 'sometimes' the marketing strategy, and 17.4 percent said that this 'never' was part of the pitch."
} 
shelters are expensive to develop; these promoters are able to sell development costs in a way that in-house counsel cannot replicate." The variable cost of making a given blueprint for tax optimization available to an additional customer could be very low, and this may explain if corporations often do not innovate their own tax avoidance models themselves, but purchase the advice of expert tax consultants.

- Products: National tax legislation and international tax treaties create a tax-rule thicket and this provides many opportunities for the innovation of new tax-avoidance models. These opportunities may typically exist accidentally, but need to be uncovered. The much quoted "double Irish with a Dutch sandwich" might be a suitable illustration. ${ }^{5}$ It is hard to imagine that this tax-savings tool is the outcome of purposeful and intelligent collaboration between the tax administrations of a whole set of countries. ${ }^{6}$

- Innovators and imitators: Tax-consulting firms differ in their abilities to uncover and innovate new tax-optimization models. The large, internationally operating firms may have a big headstart in terms of skills, know-how and business contacts to explore and find such new products, whereas many other, often smaller firms, may copy the models innovated by leading firms and cannot generate new innovations.

- Regulation lag: Bankman (1999) discusses possible anti-avoidance actions, including some that address the role of consulting firms. As an example taken from the international context, the double-Irish-with-aDutch-sandwich design illustrates the lag in regulatory policy decision making and the possible implementation lag. Even after having been in

\footnotetext{
${ }^{5}$ See, e.g., Kleinbard (2011) for a description. This tax-optimization model typically has a mother company in the high-tax country, two companies in Ireland, one company in the Netherlands, and one offshore company located in a country with low or zero taxation. A specific ownership structure and different legal forms of incorporation are used to make the sandwich an effective tax-avoidance model.

${ }^{6}$ While many of the tax loopholes presumably exist unintentionally, one cannot rule out that some existing schemes are the outcome of a purposeful design and are appropriately described as the outcomes of tax competition between countries. Such tax-competition activity is not the focus of the analysis here.
} 
place for many years, when it was announced to phase out in October 2014, the plan was that it will end within four years. ${ }^{7}$

These elements point at a dynamic model of innovation and imitation of tax avoidance products by expert tax consultants, competition between these experts, and tax regulation by the government that fights these products. Several writers discuss this relationship. Hines (2004), for instance, discusses the interdependence between the innovation of tax-avoidance tools and regular governments' legislative anti-tax-avoidance efforts. He speculates about possible drawbacks of anti-tax-avoidance efforts. Curry et al. (2014) consider taxpayers' incentives to invest in tax-planning opportunities if the government can close uncovered loopholes. Their analysis confirms the potentially welfare deteriorating interdependence between investments in tax planning opportunities and the government's choice. They also look at the search for tax planning opportunities as an innovation contest, and the role of patents for tax avoidance products. ${ }^{8}$ Slemrod (2004, p. 889) suggests that "adapting theoretical models of patent races to the case of tax shelters suggest caution regarding the success of a strategy of reforming tax laws and regulations to reduce the effectiveness of elaborate tax-avoidance techniques as soon as they are identified." This paper takes up Slemrod's suggestions and considers a stylized, but formal, fully dynamic framework. Its distinguishing features are the central role of the tax consulting firms as suppliers of tax avoidance products, the distinction between innovating and imitating tax consulting firms, the multi-period structure with an infinite horizon and the differential speed of imitation and regulation.

The literature on innovation and competition provides fundamental concepts that are building blocks for the analysis in the main sections. A key consideration is that innovation is a dynamic phenomenon as has been described in many other contexts (e.g., seminal work by Harris and Vickers,

\footnotetext{
${ }^{7}$ See, e.g., The Guardian: "Ireland to abolish controversial 'double Irish' tax arrangement", October 14, 2014. (see https://www.theguardian.com/world/2014/oct/14/irelandabolish-double-irish-tax-scheme-apple, accessed on February 08, 2018, 14:27 CET).

${ }^{8}$ The dynamic nature and the asymmetries between innovators and imitators distinguish our approach further from the formal approach of a competitive market for tax planning models in Curry et al. (2014).
} 
1987, and Reinganum, 1989. For a recent meta-survey see Hong, Oxley and McCann, 2012). Our study is not meant as a contribution to the theory of innovation races or basic innovation theory, even though the specific role of the regulator as a decision maker in the innovation process in the tax-avoidance context is a new element with important implications. ${ }^{9}$

Our analysis is related to the public finance of tax competition and corporate tax avoidance and tax competition in an international context. Some authors addressed the tax competition between jurisdictions, and the role of low-tax jurisdictions for location choices, investment decisions, production output, and, ultimately, consumer welfare. Seminal theory contributions are by Slemrod and Wilson (2009) who show that haven-countries may be harmful, and Hong and Smart (2010) and Johannesen (2010) who identify reasons for why low-tax jurisdictions may have positive effects. For a discussion and overview see Keen and Konrad (2013). A further important literature analyses firms' ability to apply profit-shifting and other tax-avoidance means under various conditions (see, for a brief review and original results, Hopland et al., 2015). Much of this literature focuses on the active role of tax havens. Few papers in this literature consider the role of intermediaries in the competition between tax havens. An exception is Gresik and Konrad (2017). They study the role of consultants' targeted versus uniform fee setting rules and how these interact with the competition between tax havens. They account for the vertical structure of this specific market in which corporations pay fees to the consultants and user fees to the tax havens that add to the total cost of tax planning. They show in a static model that a commitment for uniform fee-setting rules has a strategic effect that reduces the user fees and taxes charged by tax havens in the international context. These analyses see offshore governments as active players that offer tax shelters and charge a price for it. Our analysis here dynamic and applies both to a closed economy

\footnotetext{
${ }^{9}$ Prototypically the $\mathrm{R} \& \mathrm{D}$ literature considers innovation is an improved product that makes old products obsolete or less interesting. As Hong et al. (2012, p. 421) write: "At the most basic level, all innovations or innovation processes contain three underlying elements, namely, newness, improvement and the overcoming of uncertainty." In contrast, in our context the new product is not better than the old ones, but the regulator may make old products obsolete, creating demand for new products.
} 
and to an international context. It focuses on innovative tax consulants may search for and detect new tax planning models within a the given framework of tax laws. The perspective is not one that relies necessarily on an international context with cross-border activities, even though many practical examples may come from an international setting.

The analysis is also related to the large economic and tax law literature and the lively discussion about "base erosion and profit shifting" (BEPS) that takes place both in the legal and in the economic profession (see, e.g., Ault, 2013). This policy debate is reflected in the recent report on the profit shifting project by the OEDC (2016). While this report addresses numerous institutional issues related to BEPS, including the potential role of Mandatory Disclosure Rules (see above), it does not push the role of professional tax experts into the limelight. ${ }^{10}$ The BEPS process can be seen as the "repair shop" of a single country in the national context as well as of the community of non-haven countries in the international context that aims at closing the loopholes that have been discovered and are used for aggressive tax planning.

The analysis proceeds as follows. Section 2 outlines the general framework. Section 3 sequentially considers three types of Markov perfect equilibria that emerge for different lengths of the time lag of governmental antiavoidance regulation. It compares the cases with each other and discusses incentives of the tax-consulting firms. Section 4 discusses empirically testable hypotheses that derive from these findings and concludes.

\section{The dynamic framework}

Players, actions, sequencing There are $2+n$ players: one innovative consulting firm (labelled by $L$ for "leader"), $n$ consulting firms $F_{1}$ to $F_{n}$ (for "follower") that are unable to innovate, and the regulator/government $G$. They interact in an infinite series of periods $t=1,2, \ldots$ Each period $t$ has three consecutive decision phases: an innovation phase, a legislation phase

\footnotetext{
${ }^{10}$ The role of tax professionals has become a matter of consideration as a side aspect of what is called the "Lux-Leaks" hinting at a role of one of the big four consulting companies in the context of Advance Tax Rulings by the Luxembourg tax authorities (see also, e.g., European Parliament 2015).
} 
and a market phase.

The innovation phase. Firm $L$ chooses whether to innovate $\left(\theta_{t}=1\right)$ or not to innovate $\left(\theta_{t}=0\right)$ a new tax-avoidance product in this period $t$. If firm $L$ innovates it has a fixed effort $e>0$ and as a result innovates a new tax-avoidance product successfully and with certainty. The one-singleinnovator assumption is for simplicity only. ${ }^{11}$ The vector $\boldsymbol{\theta}_{t}=\left(\theta_{1}, \ldots ., \theta_{t}\right)$ records the innovation history and is costlessly observed by all players. An innovated "product" is a blueprint for a tax-avoidance tool that uses an existing loophole in the national/international tax rules. The blueprint is under exclusive control of the innovating firm $L$ in the period $t$ in which the innovation is made. Firms $F_{1}$ to $F_{n}$ cannot imitate this blueprint in this period. The details of the blueprint become known to $F_{1}$ to $F_{n}$ in period $t+1$ and they can costlessly imitate the product that was innovated in period $t$ in period $t+1$ and all further periods. This imitation time lag defines the 'period length' for the analysis.

The legislation phase. The government $G$ chooses $\gamma_{t} \in\{0,1\}$. It takes no action in this period $\left(\gamma_{t}=0\right)$ and has no cost, or it takes action $\left(\gamma_{t}=\right.$ 1) and has a given cost of size $\lambda>0$. The choice $\gamma_{t}=1$ bans all tax avoidance products that have ever been innovated in periods up to period $t-k$. The vector $\gamma_{t}=\left(\gamma_{1}, \ldots, \gamma_{t}\right)$ protocols the history of choices and is costlessly observed by all players. The parameter $k$ measures a time lag. Three regimes are considered that differ by the length of the time lag $k \in$ $\{0,1,2\}$. If $k=0$, this allows the government to react immediately to any newly innovated tax avoidance product. The product can be banned before it can be used or imitated. If $k=1$, the government can observe and learn about tax avoidance products and can take anti-avoidance measures in the subsequent period - the lag equals the lag needed to imitate. If $k=2$, it takes two periods until a new innovation can be banned by anti-avoidance actions. For this case anti-avoidance legislation is slower than imitation. The

\footnotetext{
${ }^{11}$ The innovation phase with one firm could be replaced by one with a sector of several innovative firms. Rather than paying $e$ and deterministically finding a product, they could be in a contest. Unless this contest fully dissipates the possible innovation rents, the assumption that one firm earns the rent and the others join the group of imitatorcompetitors for this period leads to a more elaborate model, but leads to results that have very much the same flavour.
} 
three regimes will be discussed in more detail in section 3 .

The market phase. The history of innovation and regulatory legislation determines which are the tax-avoidance products that the consulting firms may legally offer to corporate firms in period $t$. We distinguish three market conditions that may prevail in a given period $t$.

Competition: All firms $F_{1}$ to $F_{n}$ and firm $L$ have at least one not-banned tax-avoidance product which they can offer to the corporate customers in period $t$. The products can be offered to any corporate firm for a marginal cost of zero. All products are assumed to be perfect substitutes from the perspective of customer firms. Firms independently choose prices $p_{L, t} \in[0,1]$ and $p_{F_{i}, t} \in[0,1]$. If a firm has several products available, as the products are perfect substitutes, we can assume without loss of generality that the firm offers them at the same price.

The buyers of the product are the corporate firms. These are price takers and not players in a game-theory sense. They are sorted uniformly along the unit interval, where the firm (of type) $x$ is characterized by its location $x \in[0,1] .{ }^{12}$ If firm $x$ does not purchase a tax-avoidance product, it pays the corporate tax. The size of the corporate tax is normalized to $T=1$ for each firm. If firm $x$ purchases the product from consulting firm $J \in\left\{L, F_{1}, \ldots, F_{n}\right\}$ then it pays zero taxes, but pays the product price $p_{J, t}$, and, in addition, has a transaction cost of size $x$. This transaction cost reflects that a specific financial or legal structure is required for the use of the tax avoidance product, and that this structure is not necessarily optimal, for instance, from the perspective of corporate governance. As the tax burden is normalized to 1 , firm $x$ 's maximum willingness to pay for the tax avoidance model is $(1-x)$. Depending on $x$ and the prices, any firm $x \in[0,1]$ purchases the product from the least-price supplier firm or does not purchase a tax avoidance product. ${ }^{13}$

\footnotetext{
${ }^{12}$ Empirically, the market structure for tax-optimization products is likely to have many more dimensions: the market is likely to be horizontally and vertically differentiated, with multiple heterogenous products and several dimensions of heterogeneity on the demand side. The stylized assumptions about market structure are chosen here to focus on the role of relative length of delays in imitation and tax regulation and to analyse the alignment of interests between innovator consultants and the government.

${ }^{13}$ The interpretation is that these products last for one period only. The formal set-up and the description for the market had to be adjusted if tax-optimization models were
} 
The resulting market demand and firms' shares in it are,

$$
D_{L, t}=\left\{\begin{array}{ccc}
\max \left\{1-p_{L, t}, 0\right\} & \text { if } & p_{L, t}<\min \left\{p_{F_{1}, t}, \ldots, p_{F_{n}, t}\right\} \\
\max \left\{\frac{1-p_{L, t}}{\# m}, 0\right\} & \text { if } & p_{L, t}=\min \left\{p_{F_{1}, t}, \ldots, p_{F_{n}, t}\right\} \\
0 & \text { if } & p_{L, t}>\min \left\{p_{F_{1}, t}, \ldots, p_{F_{n}, t}\right\}
\end{array}\right.
$$

and

$$
D_{F_{i}, t}=\left\{\begin{array}{ccc}
\max \left\{1-p_{F_{i}, t}, 0\right\} & \text { if } & p_{F_{i}, t}<\min \left\{p_{L, t}, p_{F_{j}, t}\right\} \\
\max \left\{\frac{1-p_{F, t}}{\# m}, 0\right\} & \text { if } & p_{F_{i}, t}=\min \left\{p_{L, t}, p_{F_{j}, t}\right\} \\
0 & \text { if } & p_{F_{i}, t}>\min \left\{p_{L, t}, p_{F_{j}, t}\right\}
\end{array}\right.
$$

for all $i \in\{1, \ldots, n\}$, and for all $j=1, \ldots, n$ with $j \neq i$. Here $\# m$ is the number of suppliers who choose the same lowest price.

Monopoly: let $L$ be the monopolist supplier of tax-avoidance tools in period $t$. This applies if firm $L$ innovated a new product in this period $t$ that is not banned in this same period, and all imitator firms $F_{i}$ have no product they can offer. The latter is the case if there were no innovations made prior to $t$, or if older innovations of tax-avoidance blueprints that could be imitated by firms $F_{i}$ were banned by the government and cannot be used in period $t$. For chosen price $p_{L, t} \geq 0$ any of the corporate firms $x \in[0,1]$ either pays the corporate $\operatorname{tax} T=1$ or it purchases the tax-avoidance product of firm $L$. Corporate firms act according to the same rules as previously stated for the market phase with competition. Accordingly, the turnover of the tax-consulting firms is

$$
D_{L, t}=\max \left\{1-p_{L, t}, 0\right\}
$$

and

$$
D_{F_{i}, t}=0 \text { for all } i=1, \ldots n \text {. }
$$

Note that imitator firms $F_{i}$ cannot be a supplier with market power because any available blueprint in $t$ was invented by $L$ and is therefore also available to $L$ and all other firms $F_{j}$.

No market: none of the firms can offer a tax-avoidance product in period $t$. This applies if $L$ never innovated a product, or if all innovations that have

long-lasting durable products. Corporations could delay or revise their decisions later in this case. Also the regulation that closes loopholes affects the aggregate demand for new products in this case. 
been made have been banned. It must hold that $D_{L, t}=0$ and $D_{F_{i}, t}=0$ for all $i=1, \ldots, n$ in this case.

The vector $\mathbf{p}_{t}=\left(\left(p_{L, 1}, p_{F_{1}, 1}, \ldots, p_{F_{n}, 1}\right), \ldots,\left(p_{L, t}, p_{F_{1}, t}, \ldots, p_{F_{n}, t}\right)\right)$ records the past price choices and is public information. For periods in which a firm $J$ has no product and cannot make a price offer, we denote this by $p_{J, t}=\varnothing$.

Histories and strategies The complete history in a given period $t$ is described by the combination $\left(\boldsymbol{\theta}_{t-1}, \boldsymbol{\gamma}_{t-1}, \mathbf{p}_{t-1}\right)$ at the innovation phase, by $\left(\boldsymbol{\theta}_{t}, \boldsymbol{\gamma}_{t-1}, \mathbf{p}_{t-1}\right)$ at the legislation phase, and by $\left(\boldsymbol{\theta}_{t}, \boldsymbol{\gamma}_{t}, \mathbf{p}_{t-1}\right)$ at the market phase of period $t$. Local strategies at the respective period $t$ and phase are defined by functions that map a given history into an action, for each of the players, and the collection of these local strategies defines the strategy profile.

Period payoffs and overall payoffs The period payoffs of the tax-consulting firms are

$$
\pi_{L, t}=\left\{\begin{array}{ccc}
-e \theta_{t}+p_{L, t} D_{L, t} & \text { if } & p_{L, t} \in[0,1] \\
-e \theta_{t} & \text { if } & p_{L, t}=\varnothing
\end{array}\right.
$$

and

$$
\pi_{F_{i}, t}=\left\{\begin{array}{ccc}
p_{F_{i}, t} D_{F_{i}, t} & \text { if } & p_{F_{i}, t} \in[0,1] \\
0 & \text { if } & p_{F_{i}, t}=\varnothing
\end{array} .\right.
$$

The government maximizes tax revenue net of the cost of legislation that eliminates tax loopholes to ban tax-avoidance products. It disregards the profits of the consulting firms and of the corporate firms. ${ }^{14}$ The tax revenue is equal to the number of corporate firms that do not purchase a tax-avoidance product but rather pay the $\operatorname{tax} T=1$. Analytically, the period payoff of the government $G$ is

$$
g_{t}=-\gamma_{t} \lambda+\left(1-D_{L, t}-\sum_{i=1}^{n} D_{F_{i}, t}\right) .
$$

\footnotetext{
${ }^{14}$ Consideration of a tax revenue objective is a frequently made assumption in the tax competition context and can be justified based on Public Choice arguments. In our context the assumption is made for simplicity only: for sufficiently low cost parameters, if the government maximizes the sum of domestic rents the results are qualitatively similar. This is true because the sum of rents is highest without tax avoidance, second highest in the regime with monopoly pricing, and lowest with a competitive market with wide-spread use of tax-avoidance tools.
} 
The overall payoff of a player is equal to the discounted sum of the player's period payoffs. Hence, the continuation payoff at a given period $t$ is

$$
\begin{aligned}
\Pi_{t}^{L} & =\sum_{z=t}^{z=\infty} \delta^{z-t} \pi_{L, z}, \\
\Pi_{t}^{F_{i}} & =\sum_{z=t}^{z=\infty} \delta^{z-t} \pi_{F_{i}, z}
\end{aligned}
$$

and

$$
\Gamma_{t}=\sum_{z=t}^{z=\infty} \delta^{z-t} g_{z} .
$$

Here, $\delta \in(0,1)$ is a time- and player-invariant discount factor. This completes the characterization of the components of the dynamic framework.

\section{Equilibrium}

Let us search for Markov perfect equilibria (MPE) in stationary strategies or, if a stationary equilibrium does not exist, an equilibrium in stationary cycles, for time-lag parameters $k=0, k=1$ and $k=2$. We do this sequentially for each time-lag size in a separate subsection. ${ }^{15}$

\subsection{The MPE for the regime with lag $k=0$}

For a lag-parameter $k=0$ the choice of $\gamma_{t}=1$ bans all tax avoidance products that have been innovated up to this point of time, including a possible innovation $\left(\theta_{t}=1\right)$ in period $t$.

For the formal analysis and the characterization of the stationary MPE, we need to partition the sets of all histories of a given length $\left(\boldsymbol{\theta}_{t-1}, \boldsymbol{\gamma}_{t-1}, \mathbf{p}_{t-1}\right)$ into two sets which we denote by $H_{t}^{0}$ and $H_{t}^{1}$, and which define two states of a Markov process. The set $H_{t}^{0}$ includes all histories $\left(\boldsymbol{\theta}_{t-1}, \boldsymbol{\gamma}_{t-1}, \mathbf{p}_{t-1}\right)$ for which there is no previously innovated tax avoidance model available at the

\footnotetext{
${ }^{15}$ We could look for collusive outcomes, instead, but within the framework with many possible imitators the conditions for existence of such collusive equilibrium are likely to be rather restrictive.
} 
beginning of period $t$. This may result because no innovations ever occurred prior to period $t$, or because all previously innovated products have been banned by the government. The set $H_{t}^{1}$ includes all histories $\left(\boldsymbol{\theta}_{t-1}, \boldsymbol{\gamma}_{t-1}, \mathbf{p}_{t-1}\right)$ for which there is at least one innovated tax avoidance model available at the beginning of period $t$.

Suppose the process starts with a history denoted by $H_{1}^{0}$, in which no previous innovation exists at the beginning of period $t=1 .^{16}$ The following result holds:

Proposition 1 If $\lambda \in\left(0, \frac{1}{2}\right)$ then a unique stationary Markov perfect equilibrium exists which has $\left(\theta_{t}, \gamma_{t}\right)=\left(\theta^{*}, \gamma^{*}\right)=(0,0)$ for all $t$ and payoffs $\Pi_{t}^{L}=\Pi_{t}^{F_{i}}=0$ and $\Gamma_{t}=\frac{1}{1-\delta}$.

The proof is in the appendix. The proposition establishes existence and uniqueness. The result holds for any positive innovation costs. Also the range of admissible regulatory cost is very large. ${ }^{17}$ The proposition also describes a very intuitive outcome: An MPE in which consulting firms never innovate emerges if the government can ban new innovations of tax-avoidance products before they can be offered to customers, if the cost of banning these new innovations is sufficiently low. A new product could be innovated in this equilibrium, but does not offer any reward for the innovating firm, because it is banned before it could be used. Accordingly, both consulting firms have zero profits, all corporate firms pay the tax of $T_{t}=1$ in all periods, and the present value of these taxes yields the government's payoff in the MPE. Uniqueness (among the set of stationary MPEs) is easily established in the proof by showing that any other stationary candidate MPE invites

\footnotetext{
${ }^{16}$ As can be shown, if a previous innovation exists in $t=1$, then $\left(\theta_{1}, \gamma_{1}\right)=(0,1)$ in the equilibrium and the process reaches the stationary equilibrium in $t=2$ with $\left(\theta_{t}, \gamma_{t}\right)$ $=(0,0)$ for all $t \geq 2$.

${ }^{17}$ Furthermore, by checking that one-stage deviations are not profitable, it can be shown that existence of a stationary MPE with $\left(\theta^{*}, \gamma^{*}\right)=(0,0)$ holds even if $1 / 2<\lambda<1 / 2+$ $\delta /(1-\delta)$. Intuitively, if $\theta_{t}=1$, by a choice of $\gamma_{t}=1$ the regulator can induce a state $H_{t+1}^{0}$ in period $t+1$. Together with the continuation equilibrium $\left(\theta_{t+s}, \gamma_{t+s}\right)=(0,0)$ this leads to tax revenues of $T_{t+s}=1$ for all future periods $t+s$. The costly choice $\gamma_{t}=1$ is worthwhile it if the one-time cost $\lambda$ falls short of the present value of this stream of tax revenues.
} 
profitable deviations. The no-tax-avoidance equilibrium in Proposition 1 is the benchmark for possible departures that emerge if the government has a larger regulatory time lag.

\subsection{The MPE for the regime with lag $k=1$}

For $k=1$ the choice of $\gamma_{t}$ bans all tax avoidance products that have been innovated in period $t-1$ or earlier. Let the two sets $H_{t}^{0}$ and $H_{t}^{1}$ of histories at the beginning of period $t$ as defined before. Moreover, we start with a history in the set $H_{1}^{1}$; i.e., we assume that there is one blueprint already available at the beginning of period $t=1 .^{18}$ The following result holds:

Proposition 2 If $e \in\left(0, \frac{1}{4}\right)$ and $\lambda \in\left(0, \frac{1}{2}\right)$, then a unique stationary Markov perfect equilibrium exists that has $\left(\theta_{t}, \gamma_{t}\right)=\left(\theta^{*}, \gamma^{*}\right)=(1,1)$ for all $t$ and payoffs $\Pi_{t}^{L}=\frac{1-4 e}{4(1-\delta)}, \Pi_{t}^{F_{i}}=0$ and $\Gamma_{t}=\frac{1-2 \lambda}{2(1-\delta)}$.

The proof is in the appendix. Again, the proposition covers a wide range of innovation cost up to the period-monopoly rent of the innovator and a cost of regulation up to half the size of the maximum tax revenue in a given period. ${ }^{19}$ Proposition 2 describes an MPE in which the innovative firm comes up with a newly innovated product in each period, and in which the government chooses anti-tax-avoidance regulation and bans all older, previously innovated products (if there are any). As a result, this removes all competitor products that could be imitated and offered by firms $F_{1}, \ldots, F_{n}$ in the market in any given period. But due to the time lag, the tax avoidance product most recently innovated cannot be banned nor imitated.

This equilibrium has synergies between innovation and regulation. The government cannot make tax-avoidance products completely unavailable for

\footnotetext{
${ }^{18}$ As can be shown, if the process starts in a history from $H_{1}^{0}$, i.e., no previously innovated history exists at the beginning of period $t=1$, then $\left(\theta_{1}, \gamma_{1}\right)=(1,0)$ in $t=1$ and the process reaches the stationary path with $\left(\theta_{t}, \gamma_{t}\right)=(1,1)$ for all $t>1$.

${ }^{19}$ For $e>1 / 4$ this stationary MPE does not exist. For such a high innovation cost in each period this cost exceeds the monopoly rent. For $e<1 / 4$ existence of the MPE also does not extend to $\lambda>1 / 2$. Suppose $\left(\theta^{*}, \gamma^{*}\right)=(1,1)$ describes an MPE for this parameter range. Then the government has a regulation cost in each period that exceeds the government's higher rent in the monopoly regime compared to the competition regime.
} 
$k=1$. However, banning the old products provides the innovating firm with market power. Compared to Bertrand competition among the tax-consulting firms, the innovating firm can choose a higher price for the tax-avoidance product and earns an innovation rent. The higher price also deters a number of corporate firms from purchasing the tax-avoidance product. These firms rather pay the regular amount of taxes. In conclusion, closing tax loopholes is beneficial for both the government and the innovative tax-consulting firm.

\subsection{The MPE for the regime with lag $k=2$}

Let us now turn to the case with time-lag $k=2$. This larger time-lag reduces the government's ability to timely ban existing tax avoidance products. A tax avoidance product which is innovated in period $t$ can be offered to corporate customers by firm $L$ (and only by this firm) in the innovation period $t$. And this tax avoidance product will also be available in period $t+1$. In period $t+1$ all firms $L$ and $F_{1}$ to $F_{n}$ will be able to offer this product to corporate customers. The earliest moment when the government can regulate and ban this product is period $t+2$. The implication of lag $k=2$ is that any product that is innovated may potentially yield innovation rents for the innovator firm at the time when it has just been innovated, but the product will also be available in the next period and will cause Bertrand competition between $L$ and $F_{1}$ to $F_{n}$ in this next period.

Before we turn to the equilibrium results, we define a more fine-grained partition of the set of histories $\left(\boldsymbol{\theta}_{t-1}, \boldsymbol{\gamma}_{t-1}, \mathbf{p}_{t-1}\right)$ at the beginning of each period $t$. This partition constitutes the Markov states. We distinguish between four subsets of histories at the beginning of any given period $t$ which we denote by $H_{t}^{00}, H_{t}^{10}, H_{t}^{01}$, and $H_{t}^{11}$. The first superscript $x$ in $H_{t}^{x y}$ refers to whether there is a tax avoidance product that is at least two periods old and has not been banned previously. The second component $y$ refers to $\theta_{t-1} \in\{0,1\}$, i.e., whether $L$ innovated in period $t-1$ or not. More in detail, the set $H_{t}^{00}$ includes all histories with no blueprints that were innovated in period $t-2$ or earlier and are available at the beginning of period $t$, and with $\theta_{t-1}=0$. The set $H_{t}^{10}$ includes all histories for which at least one blueprint was innovated in $t-2$ or earlier, and is still available at the beginning of 
period $t$, and with $\theta_{t-1}=0$. The set $H_{t}^{01}$ refers to the set of histories for which no blueprints are available at the beginning of $t$ that are older than one period, and $\theta_{t-1}=1$. The set $H_{t}^{11}$ refers to the set of histories at the beginning of period $t$ such that at least one blueprint exists and is available at the beginning of $t$ that is older than one period, and $\theta_{t-1}=1$.

A first observation is a non-existence result of stationary equilibria.

Proposition 3 If $e \in\left(0, \frac{1}{4}\right)$ and $\lambda \in\left(0, \frac{1}{2}\right)$, then a Markov perfect equilibrium in stationary strategies does not exist for a lag $k=2$.

The proof is in the appendix. A stationary equilibrium is characterized by $\left(\theta_{t}, \gamma_{t}\right)=\left(\theta^{*}, \gamma^{*}\right)$, at least from a certain $t$ on. The proof shows that any such stationary equilibrium candidate offers profitable one-stage deviations either for firm $L$ or the government $G$ or for both of them. This non-existence result hints at the possibility of more interesting equilibria with a more dynamic time structure. Indeed, we find that the equilibrium that emerges is characterized by cycles, in which periods with widespread tax avoidance alternate with periods with innovation, regulatory intervention and more limited amounts of tax avoidance.

For the characterization of an MPE with such cycles we assume that the process starts from a history $h_{1} \in H_{1}^{10}$, i.e., in period $t=1$ there is at least one innovation available that is old enough such that it can be banned by regulatory action in period $t=1$ and would be available to both firms if not banned, and there is no recent innovation from the previous period that can be imitated by firms $F_{1}$ to $F_{n}$ in period $t$ but cannot yet be banned in $t$ through regulatory action, due to the time lag of regulatory measures. Given this starting condition ${ }^{20}$ the following holds:

Proposition 4 Let $e \in\left(0, \frac{1}{4}\right)$ and $\lambda \in\left(0, \frac{1}{2}\right)$. An MPE with stationary cycles exists in which $\left(\theta_{t}, \gamma_{t}\right)=(1,1)$ for all uneven periods $t=1,3,5, \ldots$ and $\left(\theta_{t}, \gamma_{t}\right)=(0,0)$ for all even periods $t=2,4, \ldots$.

\footnotetext{
${ }^{20}$ As can be shown and is implied by the reasoning in the proof, if the process starts in $H_{1}^{01}$, then the behavior in even and odd periods is interchanged. If the process starts in a state other than $H_{1}^{10}$ or $H_{1}^{01}$, then the actions in period $t=1$ move the process to state $H_{2}^{10}$ or $H_{2}^{01}$ in period $t=2$ and the stationary cycle begins there.
} 
The proof is in the appendix. Again, the proposition covers the wide range of innovation cost up to the period-monopoly rent of the innovator and a cost of regulation up to half the size of the maximum tax revenue in a given period. ${ }^{21}$ The proposition characterizes an equilibrium in which the prevalence of tax avoidance, innovation, regulation, firm profits and tax revenues fluctuates over time. In one period tax avoidance products are widely available, their equilibrium market price is zero and all corporate customer firms use these products to avoid taxation. The tax revenue is very low, as none of the corporate firms pays taxes. However, the blueprints used in this period are old blueprints, and sufficiently well-known such that the government can use anti-avoidance regulation to ban them in the next period. This is what the government will do. This, in turn, is anticipated. Hence, in the same period when this ban is enacted, the innovative firm among the tax consulting industry invents a new blueprint. As all the widely known and generally available products will be taken off the market, the innovator firm earns entrepreneurial rents on this newly innovated product. It takes yet another period until this new product is available for the tax consulting sector more generally, and one further period until this new product can again be banned, and so on.

\subsection{Regime comparisons and the tax-consulting firms' incentives}

The key institutional characteristic studied here is the size of the regulatory lag, compared to the time lag it takes to imitate newly invented products.

If the government can react instantaneously, it will - unless the regulatory cost is excessive. As this is anticipated, there will be no innovation. The government likes this equilibrium: it has zero tax avoidance, zero regulation costs for the government and zero innovation costs for consulting firms.

To react instantaneously might be difficult, however: a tax-consulting

\footnotetext{
${ }^{21}$ Again, higher $e$ or higher $\lambda$ allow for profitable deviations from this equilibrium: $e>1 / 4$ makes the innovation cost higher than the maximum innovation rent that can emerge, given that the product is freely imitated after one period. And the regulator also has payoff-increasing deviations from the cycle if $\lambda>1 / 2$.
} 
firm may develop some custom-made tax optimization solution for a specific customer and may charge this customer a high fee. The ideas developed in this context may later turn into a widespread and more easily observed standardized product. However, at the early design stage, when the product is developed on demand and for the needs of a single client/customer, this is difficult to observe, and it might be also difficult to close the tax loopholes at this early point of time. This suggests that the government may not be able to react instantaneously. Also, this is where the adoption of mandatory disclosure rules for aggressive tax planning may change the 'rules of the game' and speed up the government's anti-tax avoidance regulation. As long as there is a regulatory lag that is long enough for the innovator to recover at least the innovation cost, then this triggers a permanent innovation/regulation loop. The innovator typically earns positive rents in every period this case.

An even larger regulatory lag leads to more complex equilibrium behavior that is characterized by stationary cycles. Periods with cheap and abundant tax avoidance products and almost complete tax-avoidance behavior alternate with periods with high regulatory effort, expensive and new taxavoidance products and reduced prevalence of tax-avoidance activity. ${ }^{22}$

Overall, this hints at a partial congruence of the interests of a revenueoriented government and of consulting firms with the high innovative capabilities about the optimal size of $k$. The government prefers the regime with $k=0$ to $k=1$ and $k=1$ to $k=2$. An innovative firm prefers $k=1$ to $k=2$, but both $k=1$ and $k=2$ to $k=0$.

The innovator wants to earn the innovation rents in the period between innovation and imitation. And the innovator firm needs the government to remove tax-avoidance products once they can be offered by the imitating competitors to make space for a new innovation. If the size of the regulation lag $k$ is endogenous and can be influenced, the innovative consulting firm, but not the other consulting firms, has an incentive to inform the government

\footnotetext{
${ }^{22} \mathrm{~A}$ generalization of the result towards lags of more than two periods is intuitively straightforward. The competition phases with cheap and abundant avoidance products will be longer, whereas the phase with innovation and regulation between these longer competition phases remains unchanged.
} 
about existing loopholes and to reduce the government's time lag. It aims at reduction of the lag to the length of time it takes until a new innovation is imitated.

The recent debate by the OECD and by single national governments on mandatory disclosure rules for aggressive tax planning strategies can be interpreted in this context and as an attempt to shorten $k$. It is unclear and depends on the institutional environment and the precise implementation choices whether such rules reduce $k$ closer to $k=1$, or beyond this point and closer to $k=0$.

\section{Conclusions}

The analysis hints at a partial congruence of the interests that emerge between a revenue-oriented government and consulting firms with the highest innovative capabilities if the regulatory lag for anti-avoidance legislation is very long. The main channel that aligns their interests is the pricing for tax-optimization solutions in the market for such consultancy services. If widely-known optimization solutions that have become standard products and have been cheap due to much competition between the tax consultants are banned, this leads to a more concentrated market with higher prices. It creates a demand for new aggressive tax-planning models, and a firm that is sufficiently innovative to offer solutions in this market earns entrepreneurial rents. Such rents were absent as long as the standard products were legally feasible solutions. Furthermore, the high market price for such more innovative products prevents a share of corporate customers from purchasing such solutions; instead, they comply and pay their taxes. Hence, tax regulation that removes the better-known and more widely available tax-avoidance products from the market provides innovative tax-consulting firms with opportunities to earn innovation rents. It makes these innovative consulting firms the main beneficiaries of tax regulation. The tax authorities also benefit from this type of regulation, because more corporations abstain from this market and prefer to pay their taxes.

The analysis here is stylized and makes many assumptions that are for the sake of brevity. Some of the assumptions have been discussed throughout the 
previous sections. The main insight summarized here can be expected to be robust to many modifications of the formal analysis. To account for possible modifications will also have implications for what kind of model predictions can be expected to have empirical counterparts. The tax-consulting market is likely to consist of many parallel markets, each similar to the stylized market that was analyzed here. These markets might even overlap and interact with each other. The various products in these markets could be unrelated or weak substitutes, addressing different tax-optimization problems. Hence, even if each of these markets is characterized by product cycles such as in the equilibrium in Proposition 4, unless the cycles in the different markets are synchronized, cyclicity would not be picked up in data about aggregate profits or pricing in the tax consulting business.

Nevertheless the analysis makes some clear predictions that could, in principle, be tested. In particular, it suggests diverging interests between highly innovative consulting firms and the less sophisticated competitors. If firms can be categorized along this dimension, the formal results make predictions about consulting firms' views on the introduction of mandatory disclosure rules and about firms' influence activities and information policies. The highly innovative firms might like to be closely connected with the government. They might act as consultants for the government and might allude the government to the existing tax loopholes or inform the government how such loopholes can be closed. Even though they act as representatives of a special interest group, the government could trust these firms and listen to them. Furthermore, the analysis suggests a specific type of information policy: the highly innovative firms may try to influence the tax authorities to ban products that are so commonly available in the industry that no innovation rent is left in the market for these products. And it suggests that a regulatory policy that bans specific existing products that address a particular tax issue is followed by a surge of innovation activity inside the group of top firms on particularly this tax issue. 


\section{Appendix}

Proof of Proposition 1 Suppose that players follow the behavior that is described in the candidate equilibrium in periods after $t$. This behavior defines the continuation value (i.e., the present value in period $t+1$ of the sum of this period and future periods' payoffs) for $L$ as

$$
\Pi_{t+1}^{L}=0
$$

the continuation value for $F_{i}$ as

$$
\Pi_{t+1}^{F_{i}}=0
$$

for all $i=1, \ldots, n$, and the continuation value for the government as

$$
\Gamma_{t+1}=\frac{1}{1-\delta}
$$

Note next that the payoffs of all players are continuous at infinity: any possible period payoffs for the consulting firms are within finite intervals which are bounded from below by $-e$ for $L$ and 0 for each $F_{i}$, and bounded from above by 1 . The period payoff for the government is bounded from below by $-\lambda$ and from above by 1 . Moreover, the discount factor is $\delta \in(0,1)$. We can therefore rely on the one-stage deviation principle (Theorem 4.2 in Fudenberg and Tirole, 1991) such that we only need to check whether players can improve upon their payoffs in the candidate equilibrium by one-stage deviations. As described, for the formal analysis we partition the sets of all histories $\left(\boldsymbol{\theta}_{t-1}, \boldsymbol{\gamma}_{t-1}, \mathbf{p}_{t-1}\right)$ for given $t$ into two sets that we denoted by $H_{t}^{0}$ and $H_{t}^{1}$. The process is in $h_{1} \in H_{1}^{0}$ by the starting condition, and at a given period $t$ either $h_{t} \in H_{t}^{0}$ or $h_{t} \in H_{t}^{1}$ applies.

The market phase. The market game in period $t$ has no impact on whether $h_{t+1} \in H_{t+1}^{0}$ or $h_{t+1} \in H_{t+1}^{1}$. All firms maximize their period payoff by their price choices for given $\left(\boldsymbol{\theta}_{t}, \boldsymbol{\gamma}_{t}, \mathbf{p}_{t-1}\right)$. If none of the firms have a tax-avoidance product to sell then $p_{L, t}=p_{F_{i}, t}=\varnothing$ and $p_{L, t} D_{L, t}=0$ and $p_{F_{i}, t} D_{F_{i}, t}=0$. All corporate firms pay taxes. If only $L$ has a tax-avoidance product to sell then

$p_{L, t} D_{L, t}=\frac{1}{4}$ and $p_{F_{i}, t} D_{F_{i}, t}=0$ for all $i=1, \ldots, n$ and half of the corporate firms pay taxes. If more than one firm has a tax-avoidance product to sell 
then $p_{L, t}=p_{F_{i}, t}=0$ and $p_{L, t} D_{L, t}=0$ and $p_{F_{i}, t} D_{F_{i}, t}=0$ and none of the corporate firms pays taxes.

The regulation phase. Consider the payoff maximization of the government in period $t$ anticipating the market phase in $t$ as just described and that all players follow the candidate equilibrium in all future periods $t+1, \ldots$.

Let $h_{t} \in H_{t}^{0}$ and $\theta_{t}=0$. In this case $h_{t+1} \in H_{t+1}^{0}$, independent of $\gamma_{t}$, and the government's payoff is higher by $\lambda$ for $\gamma_{t}=0$ than for $\gamma_{t}=1$.

Let $h_{t} \in H_{t}^{0}$ and $\theta_{t}=1$. In this case $\gamma_{t}=1$ leads to $h_{t+1} \in H_{t+1}^{0}$. Hence, the government payoff is $1-\lambda+\frac{\delta}{1-\delta}$. In comparison, assuming candidate equilibrium play in the continuation game, $\gamma_{t}=0$ yields the government a payoff of $\frac{1}{2}+\delta\left(-\lambda+\frac{1}{1-\delta}\right)$. The choice $\gamma_{t}=1$ yields higher payoff than $\gamma_{t}=0$ if $1-\lambda>\frac{1}{2}-\delta \lambda$, which simplifies to $\lambda<\frac{1}{2(1-\delta)}$. This condition is weaker than $\lambda<\frac{1}{2}$ mentioned in the proposition.

Let $h_{t} \in H_{t}^{1}$ and $\theta_{t}=0$. Then the government's payoff for $\gamma_{t}=1$ as in the candidate equilibrium is $1-\lambda+\frac{\delta}{1-\delta}$. The government's one-stage payoff for $\gamma_{t}=0$ is $0-0-\delta \lambda+\frac{\delta}{1-\delta}$. So $\gamma_{t}=1$ yields a (weakly) higher profit if $\lambda<\frac{1}{1-\delta}$. Again, this condition is weaker than $\lambda<\frac{1}{2}$ mentioned in the proposition.

Finally, let $h_{t} \in H_{t}^{1}$ and $\theta_{t}=1$. Then the government's payoff in the candidate equilibrium for $\gamma_{t}=1$ is $1-\lambda+\frac{\delta}{1-\delta}$ and the government's onestage deviation payoff for $\gamma_{t}=0$ is $0-\delta \lambda+\frac{\delta}{1-\delta}$. Again, $\gamma_{t}=1$ yields a higher payoff if $\lambda<\frac{1}{1-\delta}$.

The innovation phase. Consider the innovation behavior of firm $L$. Given the equilibrium continuation play and that $\gamma_{t}=1$ if $\theta_{t}=1$, not innovating yields a higher payoff for $L$ than innovating.

We now turn to uniqueness. Any stationary equilibrium has $\theta_{t}=\theta^{*}$ and $\gamma_{t}=\gamma^{*}$ along the equilibrium path. If $\theta_{t}=\theta^{*}=0$, then the stationary equilibrium either has $\gamma_{t}=\gamma^{*}=0$, which is the equilibrium in Proposition 1 , or it has $\gamma_{t}=\gamma^{*}=1$. In this latter case a payoff increasing one-stage deviation $\gamma_{t}=0$ in period $t$ exists, as there is no product that can be banned, and the cost of anti-avoidance regulation is pure waste. Hence, we can rule out the combination $\left(\theta_{t}=\theta^{*}=0\right.$ and $\left.\gamma_{t}=\gamma^{*}=1\right)$ as a possible stationary MPE. Consider next $\theta_{t}=\theta^{*}=1$. This may go along with $\gamma^{*}=1$ or with $\gamma^{*}=0$. The case $\theta^{*}=1$ and $\gamma^{*}=1$ can be ruled out, as $\theta_{t}=0$ would 
be a payoff-increasing deviation for $L$ : any innovation is banned in the same period, so the cost of innovating is purely wasteful. The case $\theta_{t}=\theta^{*}=1$ combined with $\gamma^{*}=0$ has government's period payoffs $g_{t+s}=0$ for all $t+s>t$. A deviation to $\gamma_{t}=1$ at $t>1$ increases the government's payoff if $\lambda<\frac{1}{2}$.

Proof of Proposition 2 Any choices of actions $\left(\theta_{t}, \gamma_{t}\right)$ in period $t$ either lead to a state $h_{t+1} \in H_{t+1}^{1}$ or to a state $h_{t+1} \in H_{t+1}^{0}$. Suppose that players follow the strategies as described in the candidate equilibrium. This defines continuation values (i.e., the period- $(t+1)$ present values of the sum of period $t+1$ 's and future periods' payoffs) as follows: firm $L$ has a period profit of $\frac{1}{4}-e$ in every period. This sums up to

$$
\Pi_{t}^{L}=\left(\frac{1}{4}-e\right) \frac{1}{1-\delta}
$$

Firms $F_{i}$ 's period payoffs are zero in all periods, so $F_{i}$ 's continuation value is

$$
\Pi_{t}^{F_{i}}=0
$$

for all $i=1, \ldots, n$. The government's period payoff depends on $h_{t} \in H_{t}^{1}$ or $h_{t} \in H_{t}^{0}$. Assuming candidate equilibrium play in all periods after $t$, the continuation value is

$$
\Gamma_{t}=\left\{\begin{array}{ccc}
\left(\frac{1}{2}-\lambda\right) \frac{1}{1-\delta} & \text { if } & h_{t} \in H_{t}^{1} \\
\frac{1}{2}+\left(\frac{1}{2}-\lambda\right) \frac{\delta}{1-\delta} & \text { if } & h_{t} \in H_{t}^{0}
\end{array} .\right.
$$

Note next that we can apply the one-stage deviation principle for the same reasons as in the context of the proof of Proposition 1. We now check whether players can improve upon their payoffs in the candidate equilibrium by one-stage deviations.

The market phase. The market interaction follows the logic already described and has no impact on whether $h_{t+1} \in H_{t+1}^{0}$ or $h_{t+1} \in H_{t+1}^{1}$. All firms maximize their period payoff by their price choices for given $\left(\boldsymbol{\theta}_{t}, \boldsymbol{\gamma}_{t}, \mathbf{p}_{t-1}\right)$. If none of the firms have a tax-avoidance product to sell then $p_{L, t}=p_{F_{i}, t}=\varnothing$ and their market profits are zero. All corporate firms pay taxes. If only $L$ has a tax-avoidance product to sell then $L$ 's sales profit is equal to $p_{L, t} D_{L, t}=\frac{1}{4}$ 
and the sales profit of all other firms is zero. Half of the corporate firms pay taxes. If more than one firm has a tax-avoidance product to sell then $p_{L, t}=p_{F_{i}, t}=0$ and $p_{L, t} D_{L, t}=0$ and $p_{F_{i}, t} D_{F_{i}, t}=0$ and none of the corporate firms pays taxes.

The legislation phase. Consider the optimizing behavior of the government in $t$ anticipating that consulting firms make pricing choices in period $t$ as just described and all players follow the candidate equilibrium behavior from $t+1$ onwards. Note that equilibrium continuation play from $t+1$ onwards yields the continuation values as in (14), (15), and (16).

If $h_{t} \in H_{t}^{0}$, irrespective of whether $\theta_{t}=1$ or $\theta_{t}=0$, given the time lag $k=1$, there are no products that could be banned in period $t$. The government prefers $\gamma_{t}=0$ to $\gamma_{t}=1$, as $\gamma_{t}=1$ induces a cost of $\lambda$ and does not ban any product and does not affect the market phase in period $t$ and does not change the initial condition in the subsequent period $t+1$, which is in $H_{t+1}^{0}$ if $\theta_{t}=0$ and in $H_{t+1}^{1}$ if $\theta_{t}=1$.

If $h_{t} \in H_{t}^{1}$ and $\theta_{t}=0$ then the equilibrium choice $\gamma_{t}=1$ leads to a period payoff $(1-\lambda)$ in $t$ and to $h_{t+1} \in H_{t+1}^{0}$. The government's payoff is $(1-\lambda)+\delta \frac{1}{2}+\delta^{2}\left(\frac{1}{2}-\lambda\right) \frac{1}{1-\delta}$. A deviation to $\gamma_{t}=0$ leads to symmetric Bertrand competition between consulting firms with tax revenue equal to zero in period $t$ and a history $h_{t+1} \in H_{t+1}^{1}$ in period $t+1$. Government's payoff is $0+\delta\left(\frac{1}{2}-\lambda\right) \frac{1}{1-\delta}$. A comparison shows

$$
(1-\lambda)+\delta \frac{1}{2}+\delta^{2}\left(\frac{1}{2}-\lambda\right) \frac{1}{1-\delta}>0+\delta\left(\frac{1}{2}-\lambda\right) \frac{1}{1-\delta}
$$

if $\lambda<\frac{1}{1-\delta}$. This confirms the optimality of $\gamma_{t}=1$ for $h_{t} \in H_{t}^{1}$ if $\theta_{t}=0$.

If $h_{t} \in H_{t}^{1}$ and $\theta_{t}=1$ then the equilibrium choice $\gamma_{t}=1$ leads to a monopoly of firm $L$ in this period $t$ and to $h_{t+1} \in H_{t+1}^{1}$. The government's payoff is $\frac{1}{2}-\lambda+\delta\left(\frac{1}{2}-\lambda\right) \frac{1}{1-\delta}$. A deviation $\gamma_{t}=0$ leads to symmetric Bertrand competition between consulting firms with tax revenue equal to zero in period $t$ and to $h_{t+1} \in H_{t+1}^{1}$. The government's payoff is $0+\delta\left(\frac{1}{2}-\lambda\right) \frac{1}{1-\delta}$. The payoff for $\gamma_{t}=1$ exceeds the payoff for $\gamma_{t}=0$ if $\frac{1}{2}>\lambda$.

The innovation phase. Turn now to the innovation choice of firm $L$ in period $t$. Consider deviations from $\theta_{t}=1$. If $h_{t} \in H_{t}^{1}$, then both $\theta_{t}=1$ and $\theta_{t}=0$ are followed by $\gamma_{t}=1$. For $\theta_{t}=1$ the payoff for $L$ is $\left(\frac{1}{4}-e+\delta \Pi_{t}^{L}\right)=$ $\Pi_{t}^{L}$. For $\theta_{t}=0$ the payoff is $0+\delta \Pi_{t}^{L}$. Hence, $\theta_{t}=1$ leads to higher payoff 
for $L$ than $\theta_{t}=0$ if $\frac{1}{4}>e$. If $h_{t} \in H_{t}^{0}$, the choice of $\theta_{t}=1$ is followed by $\gamma_{t}=0$ and by $h_{t+1} \in H_{t+1}^{1}$, and yields firm $L$ a payoff of $\frac{1}{4}-e+\delta \Pi_{t}^{L}=\Pi_{t}^{L}$. The choice of $\theta_{t}=0$ is followed by $\gamma_{t}=0$ and $h_{t+1} \in H_{t+1}^{0}$. It yields firm $L$ a payoff of $0+\delta \Pi_{t}^{L}$. Accordingly, the candidate equilibrium choice $\theta_{t}=1$ yields higher payoff than $\theta_{t}=0$ if $\frac{1}{4}>e$.

This completes the analysis of possible one-stage deviations in period $t$ and shows that deviations are unprofitable for the deviating player if $e<\frac{1}{4}$ and $\lambda<\frac{1}{2}$.

We now turn to uniqueness. Any stationary equilibrium must have $\theta_{t}=\theta^{*}$ and $\gamma_{t}=\gamma^{*}$ along the equilibrium path. If $\theta_{t}=\theta^{*}=1$, then the stationary equilibrium either has $\gamma_{t}=\gamma^{*}=1$, which is the equilibrium in Proposition 2. Or it has $\gamma_{t}=\gamma^{*}=0$. In this case a one-stage deviation $\gamma_{t}=1$ in period $t$ exists that increases the period payoff for the government from 0 to $\frac{1}{2}-e$. Hence, we can rule out $\left(\theta_{t}=\theta^{*}=1\right.$ and $\left.\gamma_{t}=\gamma^{*}=0\right)$ as a possible stationary MPE. Consider next $\theta_{t}=\theta^{*}=0$. The case $\theta^{*}=0$ and $\gamma^{*}=1$ can be ruled out, as it allows for a one-stage deviation towards $\gamma_{t}=0$ which increases the government's period payoff from $-\lambda$ to 0 in the respective period. Finally, consider $\theta^{*}=0$ and $\gamma^{*}=0$. Given $h_{1} \in H_{1}^{1}$, this yields period payoffs for firms $F_{i}$, for firm $L$, and for the government that are equal to zero in all periods. In comparison, a one-stage deviation to $\gamma_{t}=1$ increases the government's period payoff to $1-\lambda$. Note that the suboptimality of $\theta^{*}=\gamma^{*}=0$ does not hinge on the starting condition. Should $h_{1} \in H_{1}^{0}$, then a deviation towards $\theta_{t}=1$ increases the payoff of firm $L$ in period $t$ to $\frac{1}{4}-e>0$, and the firm's continuation payoff cannot fall below zero. In sum this rules out any stationary MPE other than $\left(\theta^{*}, \gamma^{*}\right)=(1,1)$ for $e<\frac{1}{4}$ and $\lambda<\frac{1}{2}$.

Proof of Proposition 3 The four candidates for a stationary MPE are $\left(\theta^{*}, \gamma^{*}\right) \in\{(0,0),(1,0),(0,1),(1,1)\}$. We rule them out one after the other.

(i) If $\left(\theta^{*}, \gamma^{*}\right)=(0,0)$, then, after a finite number of periods and depending on the initial conditions that apply, in period $t$ the process is either in the set of histories $H_{t}^{00}$ (this happens if no tax-avoidance product was ever innovated prior to $t=1$ ), or the process is in the set of histories $H_{t}^{10}$ (this happens if a tax-avoidance product existed already in $t=1$ ). For $h_{t} \in H_{1}^{00}$, the 
equilibrium continuation payoff of player $L$ in the candidate equilibrium is $\Pi_{t}^{L}=0$. A profitable one-stage-deviation for player $L$ that yields at least a payoff of $\frac{1}{4}-e$ is, hence, $\theta_{t}=1$. For $h_{t} \in H_{1}^{10}$, the equilibrium continuation payoff of player $G$ in the candidate equilibrium is $\Gamma_{t}=0$. A profitable onestage deviation for player $G$ that increases the payoff by at least $\frac{1}{2}-\lambda$ is, hence, $\gamma_{t}=1$.

(ii) If $\left(\theta^{*}, \gamma^{*}\right)=(1,0)$, then, after a small number of periods, in period $t$ the process is in $H_{t}^{11}$ for $t$ and all future periods. The equilibrium continuation values are $\Pi_{t}^{L}=\frac{-e}{1-\delta}$ and $\Gamma_{t}=0$. A one-stage deviation $\theta_{t}=0$ increases $L$ 's payoff by at least $e$.

(iii) If $\left(\theta^{*}, \gamma^{*}\right)=(0,1)$ then, after a small number of periods, the process is in $H_{t}^{00}$ in $t$ and in all further periods. For $h_{t} \in H_{t}^{00}$, the equilibrium continuation payoff of player $L$ in the candidate equilibrium is $\Pi_{t}^{L}=0$. A profitable one-stage deviation for player $L$ is $\theta_{t}=1$, if $\frac{1}{4}-e>0$. Also player $G$ has an incentive at $h_{t} \in H_{t}^{00}$ to deviate to $\gamma_{t}=0$ and save the cost of banning non-existing products.

(iv) If $\left(\theta^{*}, \gamma^{*}\right)=(1,1)$, then, after a small number of periods the process is in $H_{t}^{11}$ in period $t$ and for all further periods. For $h_{t} \in H_{t}^{11}$, the equilibrium continuation payoffs of players $L$ and $G$ in the candidate equilibrium are $\Pi_{t}^{L}=\frac{-e}{1-\delta}$ and $\Gamma_{t}=\frac{-\lambda}{1-\delta}$. Both players have payoff-increasing opportunities for one-stage deviations if $\frac{1}{4}-e>0$ and $\frac{1}{2}-\lambda>0$.

Proof of Proposition 4 We show the existence of an equilibrium that alternates from histories in $H_{t}^{01}$ to histories in $H_{t+1}^{10}$ and back from histories in $H_{t+1}^{10}$ to histories in $H_{t+2}^{10}$, due to the following local strategies:

- The government chooses $\gamma_{t}=1$ in $t$ if and only if $h_{t} \in H_{t}^{10} \cup H_{t}^{11}$. That is, if there are blueprints old enough so that they can be banned, then the government bans them.

- The firm $L$ innovates if and only if the history $h_{t} \in H_{t}^{00} \cup H_{t}^{10}$. That is, $L$ innovates in $t$ if $L$ did not innovate in $t-1$. Firm $L$ does not innovate in $t$ if it innovated in $t-1$. 
This behavior moves the process according to the following pattern from the four sets of histories in $t$ to two sets of histories in $t+1$ :

$$
\begin{aligned}
& \text { If } h_{t} \in H_{t}^{01} \text {, then }\left(\theta_{t}, \gamma_{t}\right)=(0,0) \text { and } h_{t+1} \in H_{t+1}^{10} \text {. } \\
& \text { If } h_{t} \in H_{t}^{11} \text {, then }\left(\theta_{t}, \gamma_{t}\right)=(0,1) \text { and } h_{t+1} \in H_{t+1}^{10} \text {. } \\
& \text { If } h_{t} \in H_{t}^{00} \text {, then }\left(\theta_{t}, \gamma_{t}\right)=(1,0) \text { and } h_{t+1} \in H_{t+1}^{01} \text {. } \\
& \text { If } h_{t} \in H_{t}^{10} \text {, then }\left(\theta_{t}, \gamma_{t}\right)=(1,1) \text { and } h_{t+1} \in H_{t+1}^{01} .
\end{aligned}
$$

This mapping has the feature that the two sets of history that are visited in the future are either $H_{t+i}^{10}$ or $H_{t+i}^{01}$. We can also associate the continuation payoffs of the two relevant players $(L$ and $G$ ) given the mapping (17) for any initial state $H_{t}^{x y}$. Using the candidate equilibrium pricing behavior in the market stage which is fully determined by whether competition, monopoly or absence of market products prevails, we find:

$$
\begin{gathered}
\Pi_{t}^{L}\left(h_{t} \in H_{t}^{01}\right)=0+\delta\left(\frac{1}{4}-e\right)+0+\delta^{3}\left(\frac{1}{4}-e\right)+\ldots \\
=\delta \frac{1}{1-\delta^{2}}\left(\frac{1}{4}-e\right) \\
\Pi_{t}^{L}\left(h_{t} \quad \in H_{t}^{10}\right)=\left(\frac{1}{4}-e\right)+\delta^{2}\left(\frac{1}{4}-e\right)+\ldots \\
=\frac{1}{1-\delta^{2}}\left(\frac{1}{4}-e\right) \\
\Pi_{t}^{L}\left(h_{t} \in H_{t}^{11}\right)=0+\delta \Pi_{t}^{L}\left(h_{t} \in H_{t}^{10}\right) \\
\Pi_{t}^{L}\left(h_{t} \in H_{t}^{00}\right)=\left(\frac{1}{4}-e\right)+\delta \Pi_{t}^{L}\left(h_{t} \in H_{t}^{01}\right) .
\end{gathered}
$$

Similarly, for the government, given the choices in (17),

$$
\begin{aligned}
\Gamma_{t}\left(h_{t}\right. & \left.\in H_{t}^{01}\right)=0+\delta\left(\frac{1}{2}-\lambda\right)+0+\delta^{3}\left(\frac{1}{2}-\lambda\right)+\ldots \\
& =\delta \frac{1}{1-\delta^{2}}\left(\frac{1}{2}-\lambda\right)
\end{aligned}
$$




$$
\begin{gathered}
\Gamma_{t}\left(h_{t} \in H_{t}^{10}\right)=\frac{1}{1-\delta^{2}}\left(\frac{1}{2}-\lambda\right) \\
\Gamma_{t}\left(h_{t} \in H_{t}^{11}\right)=0+\delta \frac{1}{1-\delta^{2}}\left(\frac{1}{2}-\lambda\right) \\
\Gamma_{t}\left(h_{t} \in H_{t}^{00}\right)=\frac{1}{2}+0+\delta^{2} \frac{1}{1-\delta^{2}}\left(\frac{1}{2}-\lambda\right) .
\end{gathered}
$$

The payoffs of the players in each period are strictly bounded from above and below, and $\delta \in(0,1)$. Hence, we can apply the one-stage deviation principle and consider only such deviations from the equilibrium path. Like in the cases $k=0$ and $k=1$, the optimizing behavior of $L$ and firms $F_{i}$ for $i=1, \ldots, n$ at the market phase has no dynamic implications for the state in the next period and is fully determined by whether competition, monopoly or absence of market products prevails in the way that has been described before. So we can take the equilibrium period payoffs from market interaction into consideration and turn directly to one-stage deviations in states $H_{t}^{01}$ and $H_{t}^{10}$, first in the legislation phase, then in the innovation phase. ${ }^{23}$

Let $h_{t} \in H_{t}^{01}$. Compare the payoffs for the equilibrium choice $\gamma_{t}=0$ and a deviation to $\gamma_{t}=1$. This deviation reduces the period payoff by $\lambda$ in period $t$ and has no consequences for the state in the next period, as there is no old product that is affected by this regulatory decision. Hence, the deviation reduces the government's payoff compared to the equilibrium choice. Note also that this suboptimality of $\gamma_{t}=1$ is independent of $\theta_{t} \in\{0,1\}$ in period $t$.

Let $h_{t} \in H_{t}^{10}$. The government's continuation payoff in the candidate equilibrium with $\gamma_{t}=1$ is $\frac{1}{1-\delta^{2}}\left(\frac{1}{2}-\lambda\right)$. Consider a deviation to $\gamma_{t}=0$. If $\theta_{t}=$ 1 this leads to a state in $H_{t+1}^{11}$. Hence, government payoff is $0+\delta \Gamma_{t}\left(h_{t} \in H_{t}^{11}\right)$ $=\delta^{2} \frac{1}{1-\delta^{2}}\left(\frac{1}{2}-\lambda\right)<\frac{1}{1-\delta^{2}}\left(\frac{1}{2}-\lambda\right)$. The deviation is not profitable if $\lambda \in\left(0, \frac{1}{2}\right)$. If $\theta_{t}=0$ this deviation leads to a state in $H_{t+1}^{10}$. The resulting government payoff is $0+\delta \Gamma_{t}\left(h_{t} \in H_{t}^{10}\right)=\frac{\delta}{1-\delta^{2}}\left(\frac{1}{2}-\lambda\right)<\frac{1}{1-\delta^{2}}\left(\frac{1}{2}-\lambda\right)$ if $\frac{1}{2}-\lambda>0$. The deviation is also not profitable.

\footnotetext{
${ }^{23}$ Note that the same logic can be applied to show that one-step deviations from (17) for states $H_{t}^{00}$ and $H_{t}^{11}$ are also not profitable for $L$ or $G$. We only consider one-step deviations along the equilibrium path here.
} 
We turn to the innovation phase. Let $h_{t} \in H_{t}^{01}$. The candidate equilibrium choice of $L$ is $\theta_{t}=0$, is followed by $\gamma_{t}=0$ (as has just been shown) and moves the process to a state in $H_{t+1}^{10}$. It yields firm payoff $\Pi_{t}^{L}\left(h_{t} \in H_{t}^{01}\right)=\delta \frac{1}{1-\delta^{2}}\left(\frac{1}{4}-e\right)$. A deviation to $\theta_{t}=1$ is also followed by $\gamma_{t}=0$ (as has just been shown) and moves the process to $h_{t+1} \in H_{t+1}^{11}$. The resulting deviation payoff is $-e+\delta \frac{1}{1-\delta^{2}}\left(\frac{1}{4}-e\right)$. This shows that the equilibrium payoff exceeds the deviation payoff if $e \in\left(0, \frac{1}{4}\right)$.

Let $h_{t} \in H_{t}^{10}$. The candidate equilibrium choice of $L$ is $\theta_{t}=1$, followed by $\gamma_{t}=1$, moves the process to a state $h_{t+1} \in H_{t+1}^{01}$, and yields the firm $L$ a payoff of size $\frac{1}{1-\delta^{2}}\left(\frac{1}{4}-e\right)$. A deviation to $\theta_{t}=0$ is followed by $\gamma_{t}=1$ (as we have seen above) but moves the process to a history $h_{t+1} \in H_{t+1}^{00}$. The payoff is $0+\delta\left(\frac{1}{4}-e\right)+\delta^{2}\left(\delta \frac{1}{1-\delta^{2}}\left(\frac{1}{4}-e\right)\right)=\delta \frac{1}{1-\delta^{2}}\left(\frac{1}{4}-e\right)$. This deviation payoff is smaller than the payoff in the candidate equilibrium if $e \in\left(0, \frac{1}{4}\right)$.

\section{References}

[1] Ault, Hugh J., 2013, Some reflections on the OECD and the sources of international tax principles, reprinted from Tax Notes International, 70(2), 2013, Working Paper of the Max Planck Institute for Tax Law and Public Finance No. 201303. Available at SSRN: http://ssrn.com/abstract $=2287834$ or http://dx.doi.org/10.2139/ssrn.2287834.

[2] Bankman, Joseph, 1999, The new market in corporate tax shelters, Tax Notes, 83(12), 1775-1795.

[3] Curry, Philip A., Claire A. Hill and Francesco Parisi, 2014, Tax avoidance and the optimal design of tax law, Minnesota Legal Studies Research Paper No. 09-16.

[4] Dharmapala, Dhammika, 2014, What do we know about base erosion and profit shifting? A review of the empirical literature, Fiscal Studies, $35(4), 421-448$. 
[5] European Parliament, 2015, Special Committee on tax rulings and other measures similar in nature or effect, Draft Report on tax rulings and other measures similar in nature or effect, 2015/2066(INI).

[6] Fudenberg, Drew, and Jean Tirole, 1991, Game Theory, MIT Press, Cambridge, MA.

[7] The Group of $20 \quad$ (G20), 2009, London summit communiqué: global plan for recovery and reform. Available at http://www.g20ys.org/upload/auto /9c0ee8439921b1032fba1b8ca960ba8be8ca4e0d.pdf, accessed on September 21, 2015.

[8] Graham, John R., Michelle Hanlon, Terry Shevlin and Nemit Shroff, 2014, Incentives for tax planning and avoidance: evidence from the field, Accounting Review, 89(3), 991-1023.

[9] Gresik, Thomas A., and Kai A. Konrad, 2017, Tax havens, accounting experts, and fee-setting rules, CESifo Working Paper, Series No. 6774.

[10] Harris, Christopher, and John Vickers, 1987, Racing with uncertainty, Review of Economic Studies, 54(1), 1-21.

[11] Hines, James R. Jr., 2004, On the timeliness of tax reform, Journal of Public Economics, 88(5), 1043-1059.

[12] Hong, Qing, and Michael Smart, 2010, In praise of tax havens: international tax planning and foreign direct investment, European Economic Review, 54(1), 82-95.

[13] Hong, Shangqin, Les Oxley, and Philip McCann, 2012, A survey of the innovation surveys, Journal of Economic Surveys, 26(3), 420-444.

[14] Hopland, Arnt O., Petro Lisowsky, Mohammed Mardan, and Dirk Schindler, 2015, Income shifting under losses, NHH Discussion Paper FOR 21/2015. 
[15] Johannesen, Niels, 2010, Imperfect tax competition for profits, asymmetric equilibrium and beneficial tax havens, Journal of International Economics 81(2), 253-264.

[16] Keen, Michael, and Kai A. Konrad, 2013, The theory of international tax competition and coordination, in: Alan J. Auerbach, Raj Chetty, Martin Feldstein, and Emmanuel Saez (eds.), Handbook of Public Economics, Vol. 5. Elsevier, Amsterdam, 257-328.

[17] Kleinbard, Edward D., 2011, Stateless income, Florida Tax Review, 11(9), 699-774.

[18] KPMG, 2016, KPMG position paper on the European Commission's public consultation on disincentives for advisors and intermediaries for potentially aggressive tax planning schemes (November 10, 2016 - February 16, 2017), [https://assets.kpmg.com/content/dam/kpmg/xx/pdf/2017/02/kpmgposition-paper-on-disincentives- for-advisors-and-intermediaries-forpotentially-aggressive-tax-planning-schemes.pdf, accessed: February 09, 2018, 18:37 CET.]

[19] Lisowsky, Petro, 2010, Seeking shelter: Empirically modeling tax shelters using financial statement information, Accounting Review, 85(5), 1693-1720.

[20] Osterloh-Konrad, Christine, Caroline Heber, and Tobias Beuchert, 2017, Anzeigepflichten für Steuergestaltungen - Verfassungs- und europarechtliche Grenzen sowie Überlegungen zur Ausgestaltung, Springer Publisher, Heidelberg.

[21] OECD, 2015, Mandatory Disclosure Rules, Action 12 - 2015 Final Report, OECD/G20 Base Erosion and Profit Shifting Project, OECD Publishing, Paris.

[22] OECD, 2016, OECD secretary-general report to the G20 finance ministers. Available at http://www.oecd.org/tax/oecd-secretary-generaltax-report-g20-finance-ministers-july-2016.pdf (accessed on August 10, 2016). 
[23] Reinganum, Jennifer F., 1989, The timing of innovation: Research, development, and diffusion, in: Richard Schmalensee and Robert Willig (eds.), Handbook of Industrial Organization, Vol. 1, 849-908.

[24] Slemrod, Joel, 2004, The economics of corporate tax selfishness, National Tax Journal, 57(4), 877-899.

[25] Slemrod, Joel, and Varsha Venkatesh, 2002, The income tax compliance cost of large and mid-size businesses, Working Paper No. 914, Ross School of Business Working Paper Series.

[26] Slemrod, Joel, and John D. Wilson, 2009, Tax competition with parasitic tax havens, Journal of Public Economics, 93(11-12), 1261-1270. 